\title{
Energy recovery evaluation in an up flow microbial electrolysis coupled anaerobic digestion (ME-AD) reactor: Role of electrode positions and hydraulic retention times
}

\author{
Thangavel Sangeetha ${ }^{\mathrm{a}, \mathrm{b}}$, Zechong Guo ${ }^{\mathrm{b}}$, Wenzong Liu $^{\mathrm{a}, *}$, Lei Gao ${ }^{\mathrm{b}}$, Ling Wang ${ }^{\mathrm{b}}$, Minhua Cui ${ }^{\mathrm{b}}$, \\ Chuan Chen ${ }^{\mathrm{b}}$, Aijie Wang ${ }^{\mathrm{a}, \mathrm{b}}$ \\ ${ }^{\text {a }}$ Key Laboratory of Environmental Biotechnology, Research Centre for Eco-Environmental Sciences, Chinese Academy of Sciences, Beijing, China \\ b State Key Laboratory of Urban Water Resource and Environment, Harbin Institute of Technology (SKLUWRE, HIT), Harbin, China
}

\section{H I G H L I G H T S}

- A novel integrated upflow microbial electrolysis assisted AD reactor was designed.

- Specific emphasis was on optimizing electrode placement inside the reactor.

- Organic flow and HRT have influence on functional community distribution.

- Reactors with anodes near to influent were better in biogas generation.

- Reactors with cathodes near to influent were better in current production.

\section{A R T I C L E I N F O}

\section{Keywords:}

Integrated reactor

Bioelectrochemical system

Hydraulic retention time

Electrode position

Applied voltage

Microbial community

\begin{abstract}
A B S T R A C T
Microbial catalysed electrochemical systems are intensively used in basic and applied research as a sustainable platform for harnessing energy and generating value added bio-products. Recently more emphasis is being laid on enhancement of $\mathrm{AD}$ (Anaerobic Digestion) by integrating ME (Microbial Electrolysis) with it to convert $\mathrm{CO}_{2}$ (Carbon dioxide) directly to $\mathrm{CH}_{4}$ (Methane). This research attempts to shed light on the effects of electrode positioning and arrangement along with hydraulic retention time (HRT), on $\mathrm{CH}_{4}$ generation, and organic removal in novel microbial electrolysis coupled anaerobic digestion (ME-AD) reactors. However, the positioning and placement of electrodes in a ME-AD reactor have not yet been evaluated. Four reactors (S1, S2, S3 and S4) are designed with different electrode arrangements and run in four different HRTs (12, 18, 24 and $36 \mathrm{~h}$ ) with beer brewery wastewater as the substrate for treatment. The reactors with electrodes arranged at the bottom are better in performance than the reactors with electrodes placed at the top. They have maximum COD, TOC and Carbohydrate removal efficiencies of $92.1 \%, 64.2 \%$ and $98.9 \%$ respectively, high methane production rate (MPR) and methane yield (MY) with $304.5 \mathrm{mLCH}_{4} / \mathrm{Lreactor} /$ day and $275.8 \mathrm{~mL} / \mathrm{gCOD}$ respectively and a maximum current generation of $10 \mathrm{~mA}$, all at $36 \mathrm{~h}$ HRT. Electrode placement also has crucial roles to play in microbial community prevalence on the electrode biofilm of the reactors. Methanogens and electrogens are well enriched on the electrode biofilms of the reactors with bottom positioned electrodes, revealing the basis behind their maximum organic removal, methane production efficiencies and current generation. This study demonstrates that the optimization of appropriate electrode position and placement in ME-AD reactors is crucial for their performance and development.
\end{abstract}

\section{Introduction}

Anaerobic digestion (AD) is the conversion of organic matter in wastewater to methane-rich biogas through a series of interlinked processes like hydrolysis, fermentation, acetogenesis and methanogenesis [1]. It is a globally recognized technology for waste stabilization and biogas generation and is more controllable and sustainable way for the treatment of wastewater and bioenergy production. It has been

\footnotetext{
*Corresponding author at: Key Laboratory of Environmental Biotechnology, Research Centre for Eco-Environmental Sciences, Chinese Academy of Sciences, 18 Shuangqing Road, Haidian District, Beijing 100085, China.

E-mail address: wzliu@rcees.ac.cn (W. Liu).
} 


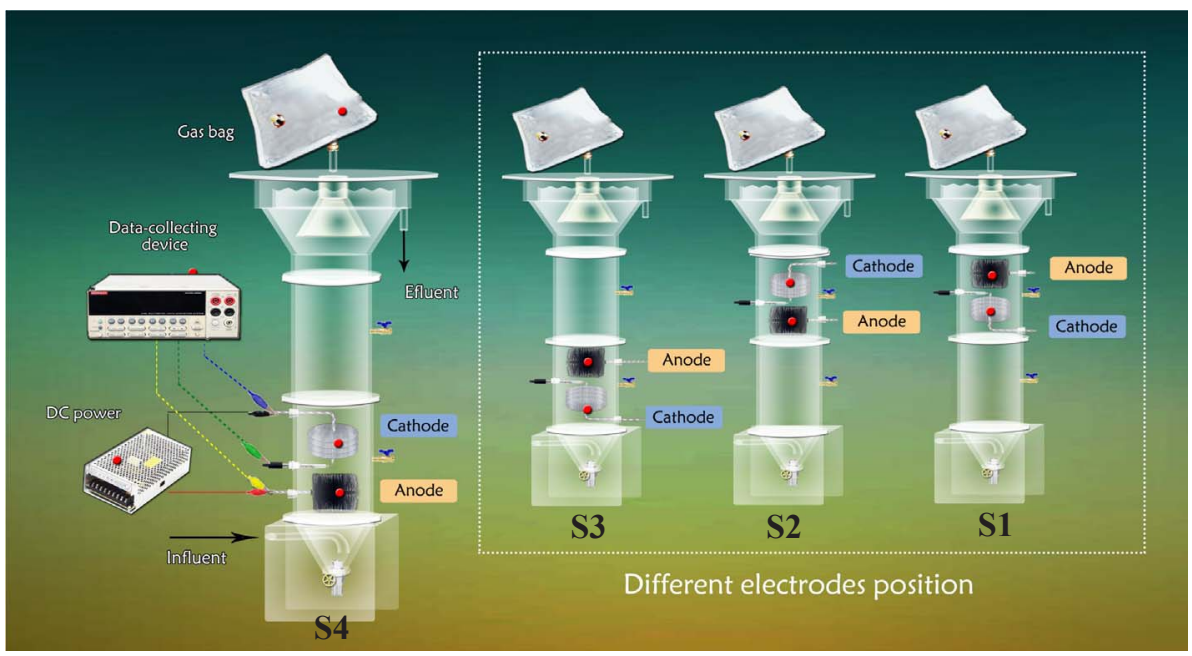

Fig. 1. Upflow microbial electrolysis assisted anaerobic reactor and electrode arrangement.

successfully applied in wastewater treatment plants and industries [2]. Recently, a novel upgrading of AD by integrating it with bio electrochemical system has been reported to accelerate biogas production $[3,4]$. Integrating the processes of AD and MECs has been proposed to enhance it in several aspects such as upgrading biogas by converting carbon dioxide into methane $[5,6]$, increasing methane production at moderate and low temperatures $[7,8]$.

Rapidly developing bio electrochemical technology is surely a promising platform for $\mathrm{CH}_{4}$ production. The addition of an external electrochemical system in an anaerobic reactor can be done to enhance microbial metabolism and wastewater treatment $[9,10] . \mathrm{CH}_{4}$ production in MECs is believed to be better enhanced than hydrogen production $[11,12]$. The microbes in the wastewater utilize the organic matter and oxidize it into $\mathrm{H}_{2}$ and $\mathrm{CO}_{2}$. With an addition of voltage, electro methanogens can use electrons, $\mathrm{H}_{2}$ and $\mathrm{CO}_{2}$ and reduce them into $\mathrm{CH}_{4}[13,14]$. Therefore, this single-chamber MEC-anaerobic reactor has a great potential to treat high-strength industrial wastewaters. It was found that $\mathrm{CH}_{4}$ production in single chamber MECs was primarily associated with current generation and hydrogen production [15]. The direct biological conversion of electrical current into methane by electro methanogenesis was observed [16]. Liu et al. improved the methane production rate by 3 times in ME-AD (microbial electrolysis coupled anaerobic digestion) reactors to treat waste activated sludge [8]. In our previous report, TOC removal of $83 \%$ and methane yield of $142.8 \mathrm{~mL} / \mathrm{gCOD}$ was achieved in upflow MEC reactors using beer wastewater [17]. It is revealed that fermentation bacteria, exoelectrogens and methanogens played the primary function to complete a flow or network of organic carbon degradation and electron transfer on complex carbon utilization [18].

Previous studies on ME-AD (microbial electrolysis coupled anaerobic digestion) reactors focussed on electrode selection and feasibility, though there is still a lack of understanding of the role of electrode arrangement in enhancing the reactor performance and special distribution of functional communities [17,19]. Electrode placement inside a reactor can be a crucial parameter as it is ought to bring upon profound consequences not only in the mass transfer and utilization of substrates but also in the production of biogas within a reactor. This may also be a crucial step in the upgrading process of the reactors. Studies were carried out to change the cathode position to harvest maximum $\mathrm{CO}_{2}$ [20] and the performance of MEC such as biogas production rate and current generation were significantly improved by electrode configurations [21]. The influence of cathode and anode size and arrangement were investigated in a flat-plate MEC [22]. Anode arrangement was optimized in a cube shaped MEC, to reduce the inner resistance to enhance $\mathrm{H}_{2}$ production [23]. So, as far as our knowledge is concerned there are no research works carried out in optimizing the electrode positions and placements in an upflow ME-AD reactor along with HRT. So, we consider this work to be a novel approach in terms of reactor construction, operation and employment of wastewater. Moreover, the identification of microbial communities on the electrodes of the reactors will further provide an in-depth understanding of the synergistic and interactive effects of microbes on reactor stability enhancement.

In the present study a process of integrating $\mathrm{ME}$ and $\mathrm{AD}$ reactors has been done for in situ conversion of organic matter into $\mathrm{CH}_{4}$ and to treat the beer industry wastewater with specific emphasis on electrode position and HRT optimization. This research work aimed at accomplishing the following such as; (i) Electrode position and arrangements can have a considerable impact on reactor stability (ii) Selection of the right HRT will be vital for reactor performance (iii) Microbial community prevalence will definitely determine the reactor performance.

\section{Materials and methods}

\subsection{Configuration and operation of the integrated reactor}

Electrochemically assisted methane production was studied with four lab scale, single-chambered tubular upflow ME-AD reactors ( $\mathrm{S}$, S2, S3 and S4). The construction was the same as our previous study, and carbon brush anodes and nickel mesh cathodes were used as electrodes after optimization in the previous study [17]. The carbon brush anodes were made of carbon fibre and were purchased from TORAY Industries, Japan. Nickel mesh was tightly woven to titanium rods, and these electrodes were placed in horizontal positions in the tubular reactor. The distance between the electrodes was $3 \mathrm{~cm}$. These rods were left out of the MFCs and clamped with crocodile clips. These clips were then connected to the external circuit and further to the channels which led to the data acquisition system. Reactor configuration was as follows (Fig. 1)

S1-Electrodes placed at the top of the reactor with anode placed above the cathode

S2-Electrodes placed at the top of the reactor with cathode placed above the anode

S3-Electrodes placed at the bottom of the reactor with anode placed above the cathode

S4-Electrodes placed at the bottom of the reactor with cathode placed above the anode

The reactors were firstly inoculated with the wastewater from the activated sludge tank of Wenchang municipal WWTP (Harbin, China) and were fed with acetate $(1500 \mathrm{mg} / \mathrm{L})$ as carbon source, in $50 \mathrm{mM}$ 
phosphate buffer solution (PBS) [24,25]. This served as inoculum for anaerobic microbes. At this stage the reactors were operated in batch mode, so as to stabilize the biofilm formation and attachment on the electrodes. The external voltage between anode and cathode was $0.80 \pm 0.01 \mathrm{~V}$. Reactors were equipped with an $\mathrm{Ag} / \mathrm{AgCl}$ reference electrode (RE-5B; BASi) for measuring anode potentials [17], which could also reveal the condition of the anode electrode [26]. All reactors were operated at a steady temperature of $30^{\circ} \mathrm{C}$, which may facilitate microbial colonization on the electrodes and enhance attachment and growth of microbial biofilm. To enhance biofilm establishment, the inoculation solution was replaced with the same fresh mixture of wastewater and growth medium and incubated under the same conditions every $24 \mathrm{~h}$ [27]. When the current generation started increasing over $2 \mathrm{~mA}$, it was considered that the electroactive biofilm was formed [25]. An anode potential via $\mathrm{Ag} / \mathrm{AgCl}$ reference electrode of below $-200 \mathrm{mV}$ indicated a successful inoculation and start up [26]. After biofilm establishment, all reactors were operated in a continuous flow mode. Duplicate reactors were operated with exactly the same conditions as the original ones. They were very necessary to prevent unexpected accidents during a long time operation, like breakages and leakages. But no electrochemical analysis or data analysis were performed with the duplicate reactors, as they were needed only during times of emergency.

Artificial Beer Wastewater influent preparation and reactor operation procedures were in accordance with our previous study [17]. The reactors were operated at four different HRTs as 12, 18, 24 and $36 \mathrm{~h}$. The reactors were operated as upflow reactors but they were not UASBs because the maximum upflow speed was $2.5 \mathrm{~cm} / \mathrm{h}$ (HRT $12 \mathrm{~h}$ ), which is too high for a UASB. Influent samples were analysed before the start of the experiment. Effluent sampling was performed at the end of every single HRT for COD, carbohydrates, TOC, VFA and ethanol analysis. Reactors were run in one single HRT for almost a month and the days with steady values (at least 3 times with standard deviation $<50 \%$ of the average) were selected for result representation purposes.

\subsection{Analysis and calculation}

Electrodes were connected to data acquisition system (Keithley instruments), over a $10 \Omega$ resistance, and the current was measured once in $10 \mathrm{~min}$. The current was represented as $\mathrm{mA}$, and the current density was calculated based on cathode area as $\mathrm{mA} / \mathrm{cm}^{2}$. Solution samples were centrifuged at $10,000 \mathrm{rpm}$, and then filtered through a $0.45 \mu \mathrm{m}$ cellulose nitrate membrane filter and finally stored at $4{ }^{\circ} \mathrm{C}$ prior to VFAs and ethanol analysis using gas chromatography [28]. COD, TOC, carbohydrates were measured along with $\mathrm{pH}$ and electrode potential measurement as per the previous research studies [29]. The VFA samples were taken from reactor and analysed consequently. Gas was collected in gas bags (Cali-5-Bond, Calibrated Instruments Inc.) attached to the top of the reactor and it was analysed by gas chromatography (Agilent 7890, USA). Gas sampling and gas volume determination was carried out with gastight syringes $(250 \mathrm{~mL}$, Hamilton Sample-lock Syringe), and its composition was calculated according to the methods prescribed [15]. The biogas in the gas bags was analysed for $\mathrm{CH}_{4}$ (methane), $\mathrm{H}_{2}$ (hydrogen) and $\mathrm{CO}_{2}$ (carbon dioxide). The methane generation has been represented as methane yield (MY), methane production rate (MPR), hydrogen yield (HY) and hydrogen production rate (HPR). As to estimate the relationship between $\mathrm{ME}$ and $\mathrm{AD}$, the methane production was calculated based on current production as indicated in Eq. (1) (with respect to electron transport).

$V_{\text {methane }}=U I t W_{\text {methane }} V_{\mathrm{m}}$

where $V_{\text {methane }}$ is the volume of methane; $U=$ external voltage; $I=$ Current; $t=$ time; $W_{\text {methane }}=4.043 \mathrm{mmol} / \mathrm{wh}$ indicates the conversion from electric heat into methane and $V_{\mathrm{m}}=22.4 \mathrm{~L} / \mathrm{mol}$ represents the molar volume of gas [30]. In order to determine the relationship between ME and methane production, the methane volume was theoretically calculated with respect to current generation considering that electrons are being donated for methane generation. It was calculated according to the equation $V=n R T / P$, where $\mathrm{V}$ is the volume of methane produced by electrons $(\mathrm{mL}), \mathrm{n}$ is the moles of methane produced, $\mathrm{R}$ is the gas constant $8.314 \mathrm{~J} / \mathrm{mol} / \mathrm{K}, \mathrm{T}$ is the temperature $(308 \mathrm{~K})$ and $\mathrm{P}$ is the atmospheric pressure $\left(10^{5} \mathrm{~Pa}\right)$ [25]. Volatile Fatty Acids (VFA) and Ethanol were analysed in the effluents of the all the reactors by a gas chromatography (Agilent 7890, USA) as mentioned in a previous study [31].

\subsection{Microbial community analysis}

The samples for microbial community analysis were taken from the anode and cathode electrodes of all the reactors at the end of the operation, by cutting a small piece of the electrode using a sterilised scissor. Considering that the presence of reactor biomass may affect the analysis for the microbial community, the electrodes were softly soaked with distilled water for $1-2 \mathrm{~min}$ prior to sampling. The genomic DNA of the samples was isolated by the Power- Soil DNA Isolation Kit (Mo Bio Laboratories, Carlsbad, CA, US) as per the manufacturer's instructions. The absorbance of the extracted DNA was measured at 260 and $280 \mathrm{~nm}$ in a spectrophotometer to check its quantity and quality. Amplicon was constructed for Illumina sequencing using bacterial fused primers $341 \mathrm{~F}\left(5^{\prime}\right.$ CCTACACGACGCTCTTCCGATCTN (barcode) CCTACGG-GNGGCWGCAG$3^{\prime}$ ) and 805R(5'-GACTGGAGTTCCTTGGCACCCGAGAATTCCA(barcode) GACTACHVGGGTATCTAATCC-3') for the V3-V4 region of the 16S rRNA gene. Polymerase Chain Reaction (PCR) was carried out with $50 \mu \mathrm{L}$ mixture containing $1 \times$ PCR buffer, $1 \mathrm{mM}$ dNTPs, $5 \mu \mathrm{M}$ each primer, $1 \mathrm{U}$ Plantium Taq, and $10 \mathrm{ng}$ of template DNA. The PCR process had an initial denaturation at $94^{\circ} \mathrm{C}$ for $3 \mathrm{~min}$, followed by 5 denaturing cycles at $94^{\circ} \mathrm{C}$ for $30 \mathrm{~s}$, annealing at $45^{\circ} \mathrm{C}$ for $20 \mathrm{~s}$, and extension at $65^{\circ} \mathrm{C}$ for $30 \mathrm{~s}$, then followed by 20 cycles of denaturing at $94^{\circ} \mathrm{C}$ for $20 \mathrm{~s}$, annealing at $55^{\circ} \mathrm{C}$ for $20 \mathrm{~s}$, and extension at $72^{\circ} \mathrm{C}$ for $30 \mathrm{~s}$, finally followed by a final extension at $72{ }^{\circ} \mathrm{C}$ for $5 \mathrm{~min}$. Prior to sequencing, the PCR products of different samples were normalized in equimolar amounts in the final mixture. Sequencing was carried out on an Illumina HiSeq 2000 apparatus [8], and the raw sequences have been deposited in the NCBI Short Read Archive (SRA) database, under the accession number PRJNA397299 (SRP115068). With similarity set at $97 \%$ and a confidence threshold of $95 \%$, the obtained sequences were phylogenetically allocated down to the phylum, class and genus level with the MOTHUR program (http://www.mothur.org/wiki/ Main_Page). Hierarchical cluster analysis of bacterial communities was based on OTUs from all electrode biofilms. The OTUs of y-axis were ordered by genus ( $3 \%$ distance). Sample communities were clustered based on complete linkage method. The color intensity of scale indicates relative abundance of each OTU read. The calculation of alpha diversity index was carried out according to the http://www.mothur.org/wiki/Calculators. The majority of analyses of DCA (Detrended correspondence analysis) were performed using $\mathrm{R}$ with functions in vegan packages, with some additional code utilizing vegan installed in pipeline of the web (ieg.ou. edu) [32].

\section{Results and discussion}

The results of this study were summed up and discussed in order to identify the best position for electrode placement and optimize the appropriate HRT with more comprehensive insights into MEC reactor performance. The effects of the electrode configurations on reactor performance were investigated in aspects of organic content removal, gas production and current generation.

\subsection{Organic content removal}

The parameters like COD, TOC and carbohydrates were analysed to calculate the organic content removal from the wastewater with respect to its configuration and retention time. The influent had a COD value of 


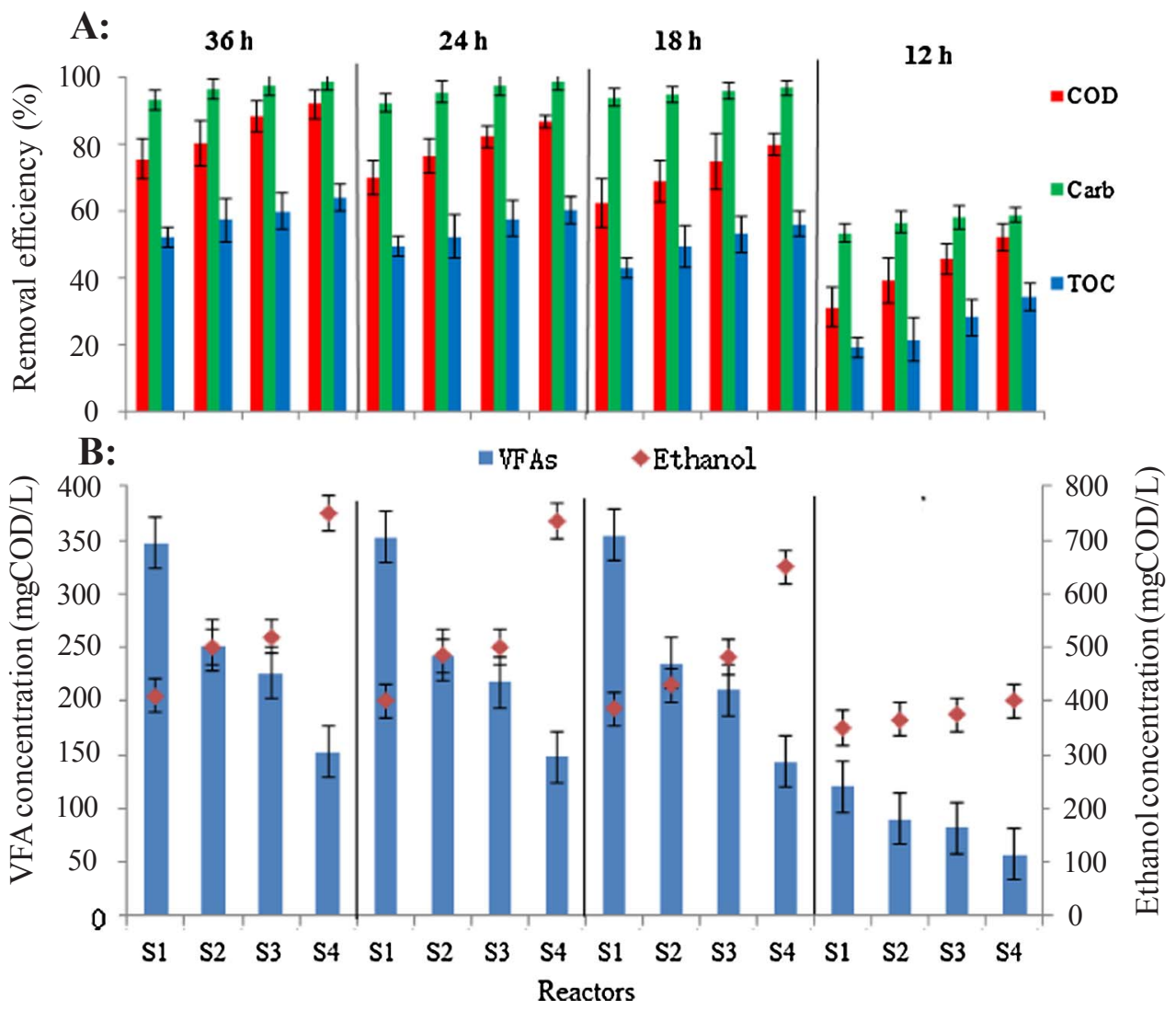

Fig. 2. Organic content removal and fermentation products of beer wastewater with respect to electrode positions and placement A: Removal of COD, carbohydrates and TOC; B: Production of Volatile Fatty Acids and Ethanol.
2200-2250 mg/L. Fig. 2(A) shows the COD, TOC and carbohydrate removal efficiencies recorded in the effluents of all the four reactors. Reactors with electrodes at bottom showed better organic removal efficiencies than reactors with electrodes at the top position. Increase in HRT resulted in a significant increase in organic content removal efficiencies. A maximum COD removal of $92 \%\left(1.35 \mathrm{gL}^{-1} \mathrm{~d}^{-1}\right)$ was documented in the effluent of S4 reactor, whereas S1, S2 and S3 effluents showed $76 \%\left(1.11 \mathrm{gL}^{-1} \mathrm{~d}^{-1}\right), 80 \%\left(1.17 \mathrm{gL}^{-1} \mathrm{~d}^{-1}\right)$ and $88 \%$ $\left(1.29 \mathrm{gL}^{-1} \mathrm{~d}^{-1}\right)$ removal efficiencies respectively at $36 \mathrm{~h}$ HRT. TOC removal also showed a similar pattern with COD removal and S4 effluent had a better efficiency with $64 \pm 8 \%$, whereas S1, S2 and S3 effluents documented $52 \pm 5 \%, 57 \pm 4 \%$ and $60 \pm 4 \%$ respectively at $36 \mathrm{~h}$ HRT. Carbohydrates removal was also influenced with the effect of electrode configuration, where the bottom electrode positioned reactors (S3 and S4) were better in removal and accounted for an average removal of $98 \%$. The top electrode placed reactors (S1 and S2) had a lesser removal efficiency of 95\%. HRT variation also resulted in a considerable change, where decreasing the HRT from $36 \mathrm{~h}$ to $12 \mathrm{~h}$ resulted in a decrease in removal efficiency in an average of $97 \pm 3 \%$ to $57 \pm 9 \%$ in all the four reactors.

A similar study has reported that a low effluent COD that included fatty acids, polysaccharides and proteins were detected in reactors with applied voltages, whereas these substances were devoid in reactors without applied voltages and AD control reactors [25]. It was also found that a decreased voltage or voltage cut off led to a lowing COD removal and complex organic degradation [19]. The reason for the increased organic oxidation in the S3 and S4 reactors, where the electrodes were arranged at the reactor bottom might be the early and easy availability of substrate for utilization by electrode respiring bacteria as the flow is in upward direction. In the reactors where electrodes are placed at the top, the organics required for oxidation were made available only when the influent left the reactor as effluent. Within this time period, a major amount of organics might have been utilized by the suspended microbes. This might be a vital reason behind the ineffective COD and TOC removal efficiencies of the S1 and S2 reactors compared with S3 and S4 reactors.

Placement of the anode below the cathode may also result in effective transfer of protons directly to the cathode and electrons through the external circuit to the cathode for further reduction. But interestingly, the organic removal rate had a downfall at $12 \mathrm{~h}$ HRT with COD, carbohydrates and TOC removals reaching an average low of $42.1 \%$, $56.6 \%$ and $25.7 \%$ respectively in all the reactors. This might be owed to the washout of substrate oxidizing microbes in both the electrode surface and the suspended liquid due to hydraulic shock at very fast flow rates. Baek et al. operated an anaerobic digester at various HRTs [33]. They assured that microbial washout was of great concern while operating an $\mathrm{AD}$ reactor, as reduction of microbial population could result in imbalanced reactions. This in turn was reflected in the reactor performance, where they witnessed a drastic decrease in COD removal rate and methane production at short HRTs.

Both HRTs and electrode placements had a definite impact on $\mathrm{pH}$, VFAs and ethanol concentration. Lower HRTs resulted in pre-acidification, causing accumulation of COD (as VFA), which eventually did not get converted to $\mathrm{CH}_{4}$ resulting in an increase in VFA, reduction in $\mathrm{pH}, \mathrm{CH}_{4}$ production and $\mathrm{COD}$ removal rate. Fig. 2(B) clearly indicates that long HRTs ( 36 and $24 \mathrm{~h}$ ) were favourable to the reactor performance and maintenance by reducing the VFAs accumulation, thereby increasing $\mathrm{CH}_{4}$ production and COD removal. Highest VFA concentration of $350 \mathrm{mg} / \mathrm{L}$ was detected in the S1 effluent at $18 \mathrm{~h} \mathrm{HRT}$, and a maximum ethanol concentration of $75 \mathrm{mg} / \mathrm{L}$ was estimated in S4 effluent at $36 \mathrm{~h}$ HRT. The $\mathrm{pH}$ was monitored in the effluent of all the reactors throughout the experiment. The effluent of S1 was observed to have the lowest $\mathrm{pH}$ between 5.0 and 5.3, which was followed by S2 between 5.5-5.9 and S3 between 6.0-6.5, and the highest $\mathrm{pH}$ was displayed by $\mathrm{S} 4$ effluent between 7.1 and 7.3. The optimum pH for the growth of methanogens was reported to be in a range of 6.0-8.6, so values below 6 and above 8.6 can negatively affect $\mathrm{CH}_{4}$ production [34]. This indicated that $\mathrm{pH}$ of the effluents of S3 and S4 were crucial 


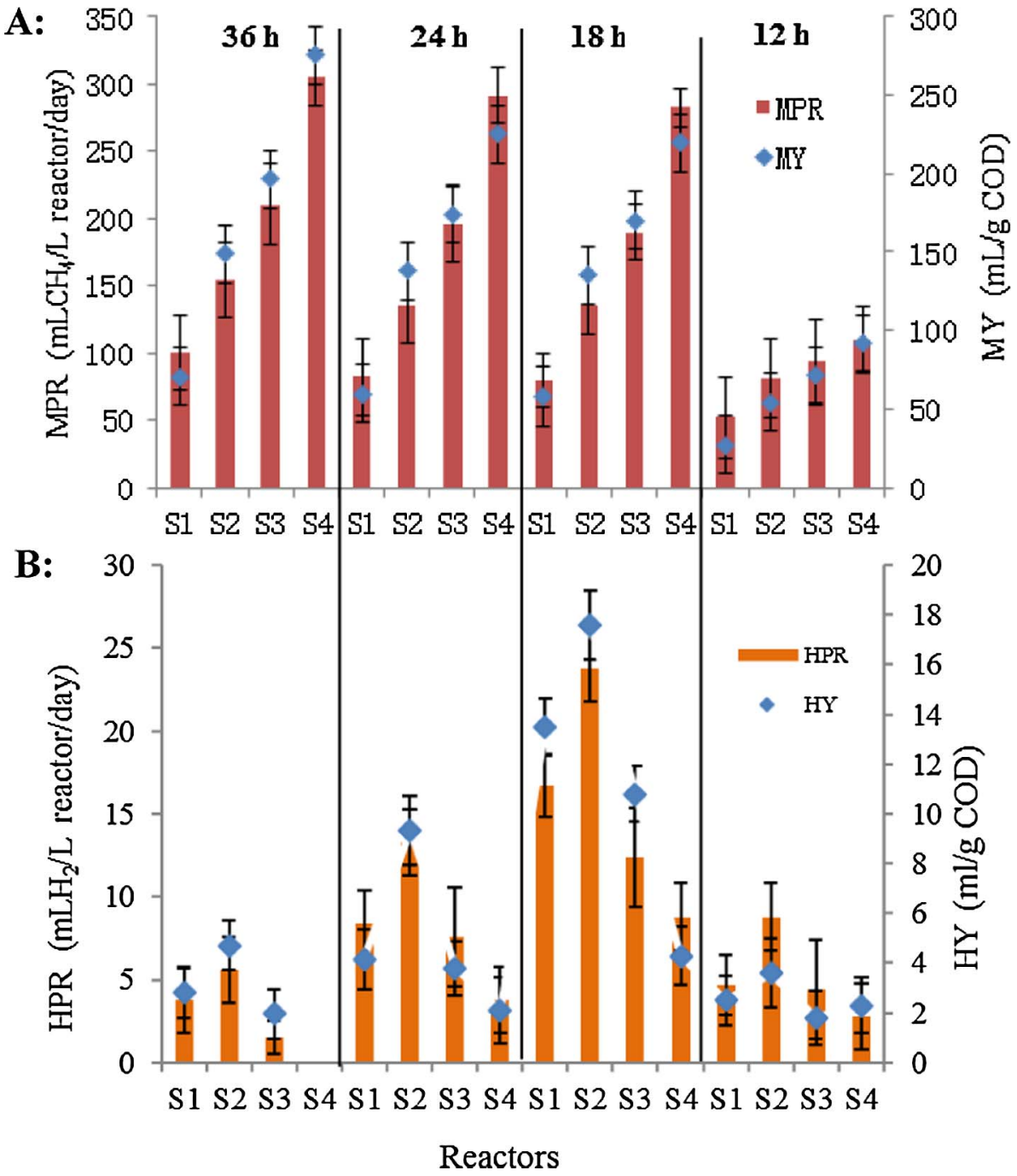

Fig. 3. Methane (A) and hydrogen (B) production in the reactors. for an efficient $\mathrm{CH}_{4}$ production and thereby better organic removal. A sudden decrease in VFAs and ethanol concentration was observed in the reactor effluents at $12 \mathrm{~h}$ HRT. Chelliapan et al. [35] operated a novel up-flow anaerobic sludge reactor (UASR) to investigate the effects of HRT on reactor performance in terms of biogas production, COD removal and VFAs concentration. They concluded that as HRT was reduced from $4 \mathrm{~d}$ to $1 \mathrm{~d}$, COD removal and biogas production were reduced, whereas VFAs concentration increased giving rise to $\mathrm{pH}$ reduction. So, from the above substantiations and results, a correlation between all operational parameters was evident.

\subsection{Biogas generation}

In the integrated systems, hydrogen that was formed by the reduction of electrons and protons at the cathode was utilized by the hydrogenotrophic methanogens along with carbon dioxide $\left(\mathrm{CO}_{2}\right)$ to produce methane, which played a positive role to accelerate methane production rate [30]. Fig. 3(A) and (B) illustrated that electrode configuration had a substantial impact on $\mathrm{CH}_{4}$ and $\mathrm{H}_{2}$ production. Increase in HRT resulted in an increase in $\mathrm{CH}_{4}$ production, with a pattern of S4 $>$ S3 $>$ S2 $>$ S1 on terms of electrode placement. Hydrogen production followed a contradictory trend to that of methane. A maximum HPR and HY of $23.8 \mathrm{mLH}_{2} /$ Lreactor/day and $17.6 \mathrm{~mL} / \mathrm{gCOD}$ were detected in $\mathrm{S} 2$ at $18 \mathrm{~h}$, indicating that hydrogen utilization was the least with the upper position of cathode at the top of reactor. In addition, low COD removal at a short HRT of $12 \mathrm{~h}$ reduced electron generation on anode and consequently hydrogen production rate while long HRTs of 24 and $36 \mathrm{~h}$ also lead to low hydrogen collection because of hydrogen utilization by suspended methanogens. Therefore, a maximum MPR of $304.5 \mathrm{mLCH}_{4} /$ Lreactor/day was yielded in the S4 reactor at $36 \mathrm{~h} \mathrm{HRT}$, and then S3 with $210.3 \mathrm{mLCH}_{4} /$ Lreactor/day; whereas the S1 and S2 reactors could attain a yield of 100.2 and $154.6 \mathrm{~mL} \mathrm{CH}_{4} /$ Lreactor/day respectively. The MY also followed a similar trend with S4 reactor achieving a maximum of $275.8 \mathrm{~mL} / \mathrm{gCOD}$ followed by S1, S2 and S3 with a production rate of $70.9,148.7$ and $196.4 \mathrm{~mL} / \mathrm{gCOD}$ respectively. Taking the above mentioned results into account it can be inferred that the arrangement of electrodes had a remarkable effect on $\mathrm{CH}_{4}$ production. Bioelectrodes at bottom position definitely took advantage to predominantly convert organics for electrons (hydrogen) production and time for hydrogen utilization in the integrated system with enhanced methane production. When anode electrode was placed above the cathode electrode and they were positioned at the top of the reactor, $\mathrm{CO}_{2}$ was not sufficiently able to react with the $\mathrm{H}_{2}$ produced by cathodic reduction to form $\mathrm{CH}_{4}$. It was detected that the biogas from $\mathrm{S} 1$ reactor had a maximum $\mathrm{CO}_{2}$ content of $6.1 \%$. Meanwhile in the electrodes configured at the reactor bottom, the $\mathrm{CO}_{2}$ that was produced from bottom biofilm communities increased the chance to be well utilized by upper microbes (suspended and biofilm) to produce $\mathrm{CH}_{4}$. Recently, a research pointed out that in the process of acidogenesis in suspended biofilms with or without applied voltage, more electrons from glucose were transferred and stored as propionate and butyrate accompanied by $\mathrm{CO}_{2}$, finally resulting in a reduced direct transfer to hydrogen or 


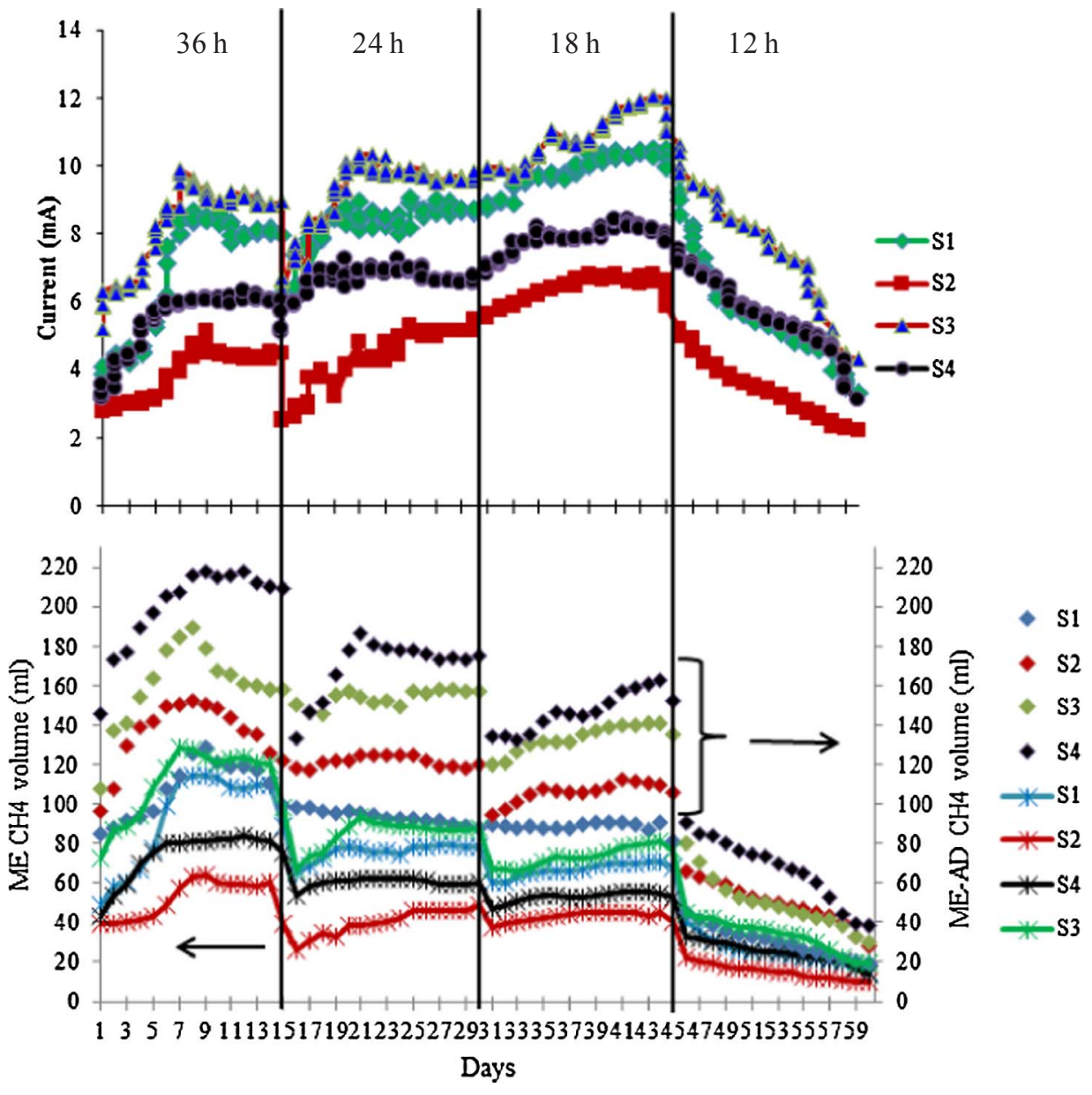

Fig. 4. Current profile of the reactors and methane production based on electron contribution (ME) and methane measurement (ME-AD) in accordance with electrodes configuration.

methane [36]. This may also be a reason for better $\mathrm{CH}_{4}$ generation in $\mathrm{S} 3$ and S4 reactors than in S1 and S2 reactors. So, these discussions well justified the better performance of $S 4$ reactor in both organic content removal and methane production compared to the other three reactors.

\subsection{Electron transfer evaluation for methane enhancement}

The current generation is illustrated in the Fig. 4, and electrode placement had an impact on it. S3 reactor was observed to produce a maximum current of $10 \mathrm{~mA}\left(0.83 \mathrm{~mA} / \mathrm{cm}^{2}\right.$ cathode), which was followed by S1 (9.0 mA, $0.75 \mathrm{~mA} / \mathrm{cm}^{2}$ cathode), S4 (8. $\mathrm{mA}, 0.67 \mathrm{~mA} / \mathrm{cm}^{2}$ cathode) and S2 (8. $\mathrm{mA}, 0.69 \mathrm{~mA} / \mathrm{cm}^{2}$ cathode). The reason behind better current production of S3 reactor can be discussed as follows. The anode was placed above the cathode in S3 reactor and we assumed that the anode respiring bacteria (ARB) on the anode might have utilized the organic content as well as the $\mathrm{H}_{2}$ produced in the cathode for the synthesis of electrons. Lee et al. found that the ARBs were utilizing $\mathrm{H}_{2}$ as the electron donor to produce electrons [20]. It was proved that $\mathrm{H}_{2}$ is a universal electron donor for anaerobic microbes and the ARB were likely to consume it for electron generation, and also justified the fact of better performance of S3 reactor in terms of current generation. As a result, parts of electrons $\left(\mathrm{H}_{2}\right)$ could be recycled between cathode and anode, such as over $100 \%$ coulombic efficiency in small single chamber reactors [25]. Therefore, electrode position and arrangement showed an important effect on current generation and gas production.

A theoretical analysis was made to evaluate and compare the methane produced from current or electron contribution (ME methane) with the methane in the gas bag (ME-AD methane) as in Fig. 4(B). Methane generation from electrons followed the similar pattern with current generation (Fig. 4A) whereas methane from $\mathrm{AD}$ followed the trend of methane generation (Fig. 3A). It was apparent that bottom electrode positioned reactors (S3 and S4) were the best in ME-AD methane production $(189 \pm 18 \mathrm{~mL}$ and $218 \pm 19 \mathrm{~mL}$ respectively) compared to the top electrode positioned reactors (S1 and S2 with $153 \pm 15 \mathrm{~mL}$ and $128 \pm 12 \mathrm{~mL}$ respectively). The reason for the maximum methane generation in bottom electrode positioned reactors might be the early and easy availability of substrate for utilization as the flow was in upward direction and the microbes took up the organics to eventually produce $\mathrm{CH}_{4}$. But in the reactors with top positioned electrodes, the substrate was better utilized by the suspended microbes than the microbes on the electrodes. S1 also had the similar electrode construction as S3, except that the electrodes were arranged at the top and it was also good in electron contributed methane production with $115 \mathrm{~mL}$. This may again be due to the utilization capacity of both the organics and $\mathrm{H}_{2}$ by the ARB to produce electrons and eventually methane by electromethanogenesis as mentioned earlier. Bioelectrochemical process has been proved to accelerate electron transfer efficiency and electrode recovery reactions $[37,38]$. An analysis into electron involvement in methane generation was carried out by in ME$\mathrm{AD}$ reactors [30]. The $\mathrm{AD}$ reactor produced $260 \mathrm{~mL}$ of methane, whereas the hybrid reactor ( $\mathrm{AD}+\mathrm{ME}$ ) produced almost double the amount of methane than the control $(564 \mathrm{~mL})$. Similarly electron contribution resulted in an elevated methane generation of $1200 \mathrm{~mL}$ in a coupled reactor, from $650 \mathrm{~mL}$ of methane in $\mathrm{AD}$ reactor [8]. Reactor S2 with a similar electrode arrangement with S4, but different position was not good at methane generation from both ME and AD. This can be justified with the result that $\mathrm{H}_{2}$ was solely detected in the biogas of this reactor and it was unavailable to the ARB for electron generation and eventually electromethanogenesis. These evidences drew out the fact that the electrodes should be positioned at the reactor bottom and the 
need to efficiently integrate $\mathrm{ME}$ and $\mathrm{AD}$ processes.

The current produced generally in all the four reactors at longer HRT $(36 \mathrm{~h})$ was lower than that produced at shorter HRT (18 h). It may be due to the fact that longer HRTs provided the substrate to the system at limiting rates, which eventually reduced the organic uptake of electrode respiring microbes. Thus eventually decreasing the electron production and thereby the current generation. The effects of HRT on power generation in an osmotic microbial fuel cell were investigated [39]. They stated that increasing the HRT from 10 to $24 \mathrm{~h}$ slightly decreased the current generation, whereas decreasing it from 24 to $6 \mathrm{~h}$, brought about a dramatic increase in current generation activity indicating that power generation was limited by organic supply. Upgrading of MFCs were performed by operating them at different HRTs [40]. Operating continuous MFCs at short HRTs, showed maximum power density due to substrate availability for anodic biofilm, resulting in higher substrate conversion efficiency and electrochemical activity, than at long HRTs. But at very short HRTs, washout of electroactive microbes occurred, resulted in rapid fall in current generation. So, the results of this study were in accordance to the above mentioned substantiations.

\subsection{Effects of electrode positioning on electrode respiring bacteria distribution}

A total of 2732 Operational Taxonomic Units (OTUs) and 2,84,074 sequences were classified in eight samples (S1 A, S2 A, S3 A, S4 A, S1C, S2 C, S3 C and S4 C), where A denoted the anode electrode and C denoted the cathode electrode of the reactor. The cathode biofilm of S1 reactor (S1C), showed the highest diversity (Shannon Index of 3.9 (Table S1)) and anode of S4 (S4A) had the lowest diversity (Shannon Index of 3.0). The relative abundances of the microbial communities were attributed to the distributions of phylum, class and order in the anode and cathode biofilms. The major phyla of anode and cathode are shown in Fig. 5. Anode biofilm was generally enriched by Firmicutes (41\%), Proteobacteria (38\%) and Bacteroidetes (16\%), whereas the cathode biofilm had the occurrences of Firmicutes (46\%), Proteobacteria (27\%) and Bacteroidetes (21\%).

To further compare and analyse the microbial communities, their distribution was identified at the class level (Fig. 5). Among the six major classes (Bacilli, Bacteroidia, Clostridia, Deltaproteobacteria, Erysipelotrichi and Gammaproteobacteria) were identified. Bacilli accounted for a maximum of $25 \%$ on anode and $30 \%$ on cathode biofilms, where S4 anode had $40.5 \%$ and S4 cathode had $38.6 \%$ of Bacilli on their biofilm. This suggested that more fermentative and oxidative communities were enriched on S4 electrodes than other electrode biofilms, suggesting enhanced organic content removal. Clostridia were enriched on S3 cathode (13.4\%) and Deltaproteobacteria on S3 anode (27\%) implying synergistic effects with exo-electrogens and better current production than other reactors. The class Bacteroidia consisted of abundant anaerobic bacteria responsible for decomposition and organic acids production [41]. S1 anode and cathode had the maximum Bacteroidia of $26.3 \%$ and $22.4 \%$ respectively on their biofilm, which further revealed the reason behind the elevated VFA concentration in S1 reactor than the other reactors. The class Erysipelotrichi belonged to phylum Firmicutes, were recognized as a common fermenting class bacteria [42], which indicated that these reactors had better fermentation ability and also validated the better ethanol production in these two reactors.

Genus level microbial analysis yielded more detailed responses to the results of this study (Fig. 5). Important electrogenic communities like Geobacter, and Desulfovibrio (Deltaproteobacteria and Gammaproteobacteria) were also enriched on S3 cathode biofilm and that may be the reason for current generation of that reactor compared to other three reactors. Geobacter was found in fewer fractions of 3.6\%, whereas Desulfovibrio was enriched with a maximum of $10.3 \%$ on S3 cathode biofilm. The most abundant genera for electron transfer were Geobacter, and Desulfovibrio [43]. Moreover, Desulfovibrio have also been reported as efficient metal-reducing bacteria [44,45].

Though Bacillus accounted for an average of only $2.0-2.15 \%$ in both anode and cathode of all reactors, Lactococcus was enriched better $(19 \%$ in anode and $15 \%$ in cathode) and it had developed the maximum in S4 anode with $24 \%$ and S4 cathode with $19 \%$, suggesting a better fermentative and oxidative efficiency than the other reactors. Lactococcus also had good enrichment in S3 electrodes with $18.5 \%$ on anode and $13.1 \%$ on cathode. This marked a synergistic activity with electrogens (Geobacter and Desulfovibrio) and it has been remarkably reported that Lactococcus lactis possessed self-catalysed anodic electron transfer by excreting redox mediators [46]. Furthermore, there was a better prevalence of Bacteroides on the electrodes of S3 and S4 (13.4\% and 14.6\% respectively) and this witnessed the better substrate degrading ability of these reactors compared with S1 and S2 reactors $(5.5 \%$ and $10 \%$ respectively) $[47,48]$. Thus, it was perceptible that the key communities detected in this research were Lactococcus and Desulfovibrio belonging to Class Bacilli and Deltaproteobacteria respectively.

\subsection{Methane production and Archaea community prevalence}

Methane was detected in all reactors after almost 15 days of operation. Fig. 6 shows the prevalence of methanogens on anode and cathode biofilm of all the reactors. Acetotrophic methanogens (Methanosarcina (facultative) and Methanosaeta (obligate)) that generate methane from acetate were predominantly found on the anode biofilm. Hydrogenotrophic methanogens (Methanobacterium, Methanobrevibacter, Methanocorpusculum and Methanospirillum), which utilized $\mathrm{H}_{2}$ for methane production were found on the cathode biofilm and they accounted for almost $80 \%$ of the total cathode biofilm diversity. The cathode of S4 had the maximum presence of hydrogenotrophic methanogens (82.5\% Methanobacterium); whereas S4 anode had the dominance of acetotrophic methanogens (39.8\% Methanosarcina). Methanobrevibacter arboriphilus species was enriched to almost $11 \%$ on S4 cathode (Data not shown). The results were further substantiated by the following studies. The first report of electromethanogenesis on a biocathode MEC was reported, where Methanobacterium palustre constituted almost $87 \%$ of the cathode biofilm, and it was identified as the primary hydrogenotrophic methanogen [16]. Jiang et al. constructed novel MFC-MEC coupled reactors with bioanodes and biocathodes for methane production and current generation [49]. Interestingly, they detected that carbon dioxide was reduced to methane in the biocathode with the aid of hydrogenotrophic methanogens like Methanobacterium palustre, Methanobrevibacter arboriphilus and Methanocorpusculum parvum. Siegert et al. have reported that Methanosarcina is both hydrogenotrophic and acetotrophic as it was reported to use both acetate and $\mathrm{H}_{2}$ for methane generation [50]. They operated mini-MECs to better understand the methanogenic communities responsible for methane generation and concluded that the presence of hydrogenotrophic methanogens will boost up methane generation in MECs. Acetotrophic methanogens (Methanosarcina and Methanosaeta) were clearly enriched on the anode biofilm of single chambered MECs used in a previous research work $[8,18]$. There were remarkable enrichments of hydrogenotrophic methanogens (Methanobacterium, Methanobrevibacter and Methanospirillum) on cathode and acetotrophic methanogens (Methanosarcina and Methanosaeta) on anode of ME-AD reactors.

\subsection{The function evaluation of functional communities at different electrode positions}

Electrode placement inside the reactor had vital impacts on the reactor performance and functional community distribution. The influence on functional communities is depicted in Figs. 7 and 8. Basically, the upper electrode position reactors S1 and S2 were clustered together (S2A, S2C, S1C and S1A) and lower electrode position reactors S3 and S4 were clustered together (S4A, S3A and S3C) (Fig. 7). It can be concluded that the electrode communities were substantially 


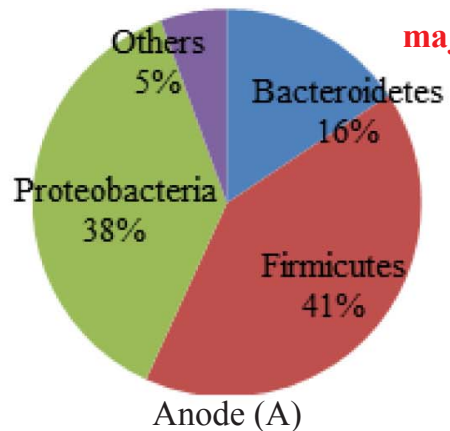

major Phyla
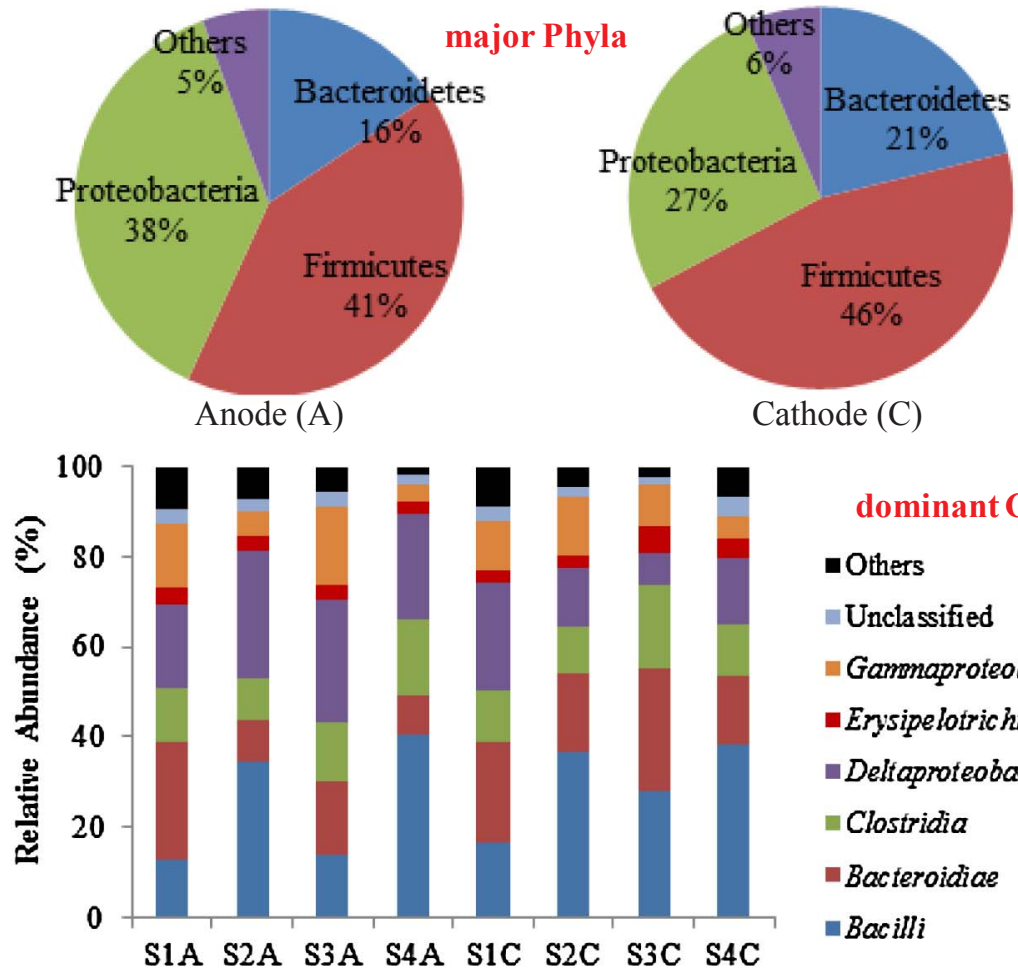

Electrode biofilms
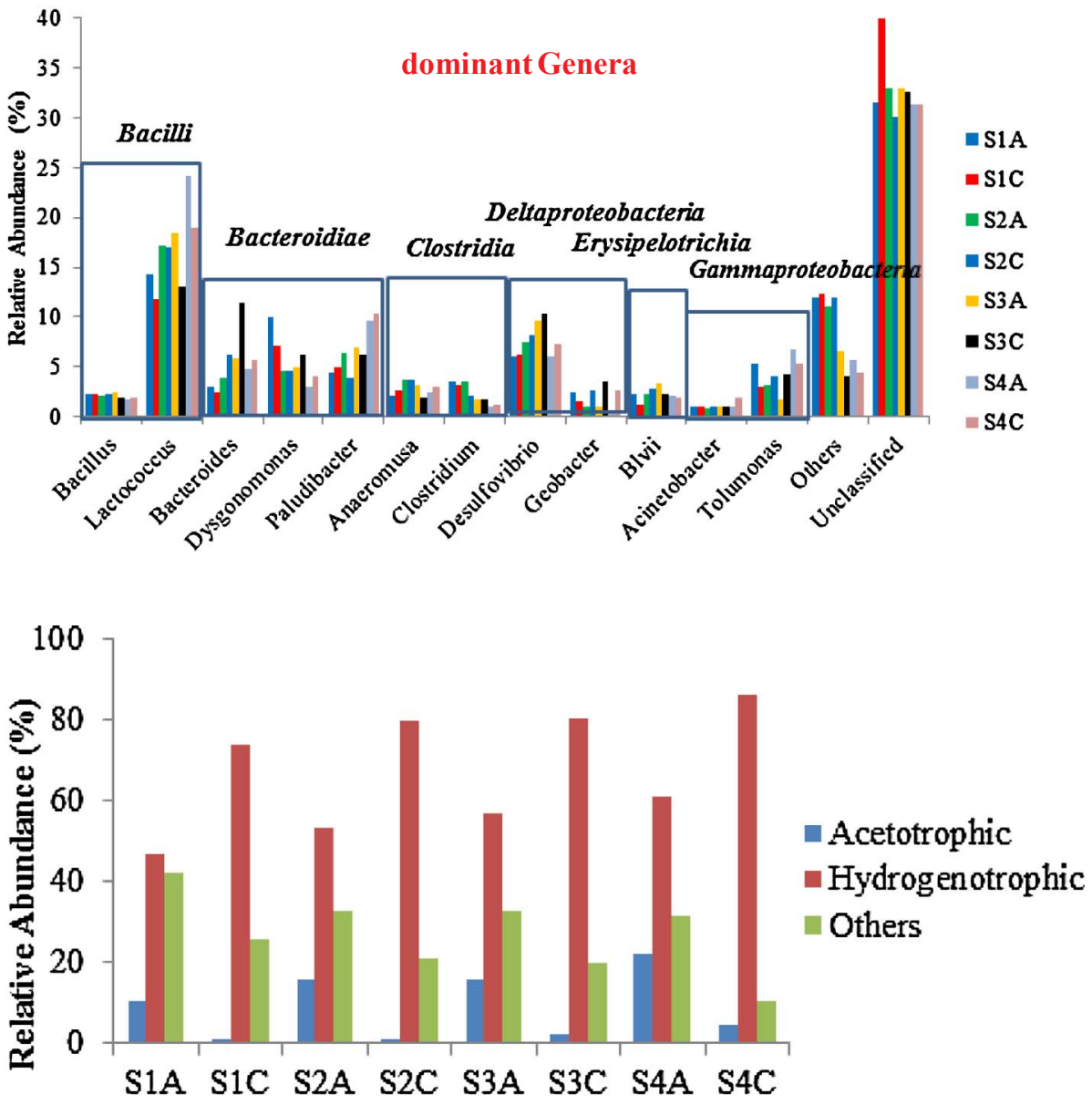

Electrode biofilms
Fig. 5. Distribution of microbial community structure in the reactor biofilms of anode (A) and cathode (C) for major Phyla, dominant Class and dominant Genera.
Fig. 6. Relative abundance of methanogens on the electrode biofilms. 


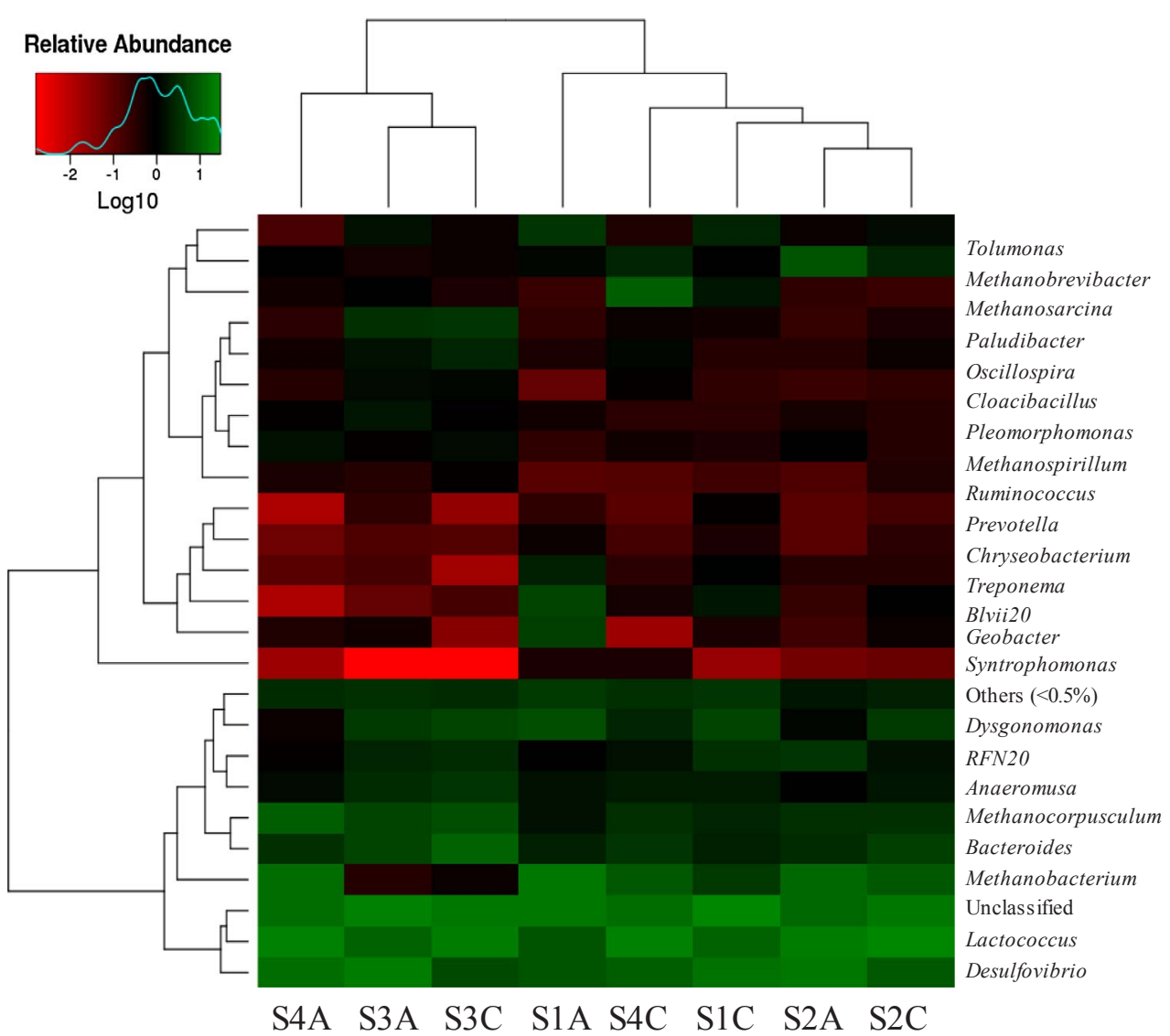

Fig. 7. Hierarchical cluster analysis of bacterial communities from all electrode biofilms. The OTUs of y-axis were ordered by phylum (3\% distance). Sample communities were clustered based on complete linkage method. The color intensity of scale indicates relative abundance of each OTU read. (For interpretation of the references to colour in this figure legend, the reader is referred to the web version of this article.)

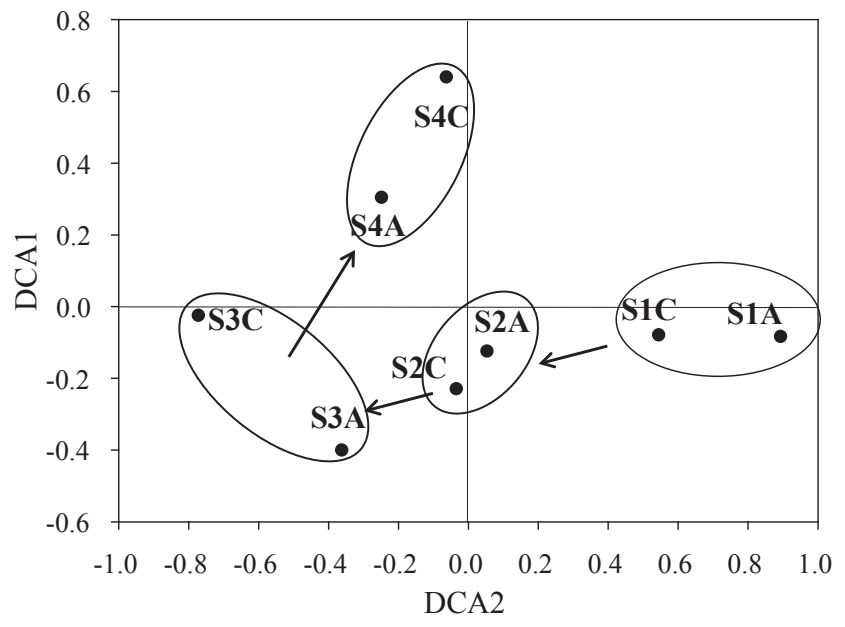

Fig. 8. Detrended correspondence analysis (DCA) of microbial communities in electrode biofilms.

determined by the electrode positions in an anaerobic system. The key functional communities were mostly methanogens, like Methanobrevibacter, Methanosarcina, Methanospirllum, Methanocorpusculum, and Methanobacterium as well as some potential exoelectrogens, like Geobacter, Desulfovibrio. Specifically, relatively higher anaerobic communities and exoelectrogens were detected in bioanodes when cathodes were placed below them, compared with cathodes placed above the anodes. A slight shift was demonstrated over different positions with different arrangements of bioanode and biocathode in the integrated system based on DCA results (Fig. 8).

It was revealed that fermentation bacteria, exoelectrogens and methanogens played the primary function to complete a pathway or network in the bioelectrochemical systems [18]. However, the results showed that COD removal, electron transfer and methane production were varied when placing electrodes in different positions with different arrangement of bioanode and biocathode. Functionally, COD removal was determined by both bioelectrochemical and anaerobic pathways; electron production due to COD conversion was mainly determined by bioanode; while the improved methane production may be due to biocathode reactions. In an up flow microbial electrolysis assisted anaerobic reactor, organics were oxidized along with the flow direction of the substrate inside the reactor (from bottom to top), and this determined the energy flow in the integrated system. A higher microbial diversity was presented in electrodes with anode placed above the cathode (Shannon index S1A of 3.7 and S1C of 3.9; S3A of 3.4 and $\mathrm{S} 3 \mathrm{C}$ of 3.5) compared with cathode placed above the anode (Shannon index S2A of 3.2 and S2C of 3.4; S4A of 3.0 and S4C of 3.5). Reactors with anodes placed near to influent inlet were better in biogas generation, but reactors with cathodes near to influent inlet were better in current production. The higher current was possibly produced by recycling cathodic gas products when cathode was below anode and it was reasonable that gas production was reduced simultaneously in S3 compared to S4. It has been reported that there is a possibility of acetate production by reducing $\mathrm{CO}_{2}$ in one of cathodic reactions in BESs [51]. As a result, microbial electrosynthesis can use cathode electrons to capture $\mathrm{CO}_{2}$ and produce multicarbon compounds as substrates for other microbial communities. For example, Methanosaeta, which cannot use hydrogen as substrate, was also detected in the cathode biofilm, where acetate was produced by homo-acetogens [52]. Therefore, the cathode recovery products (hydrogen, acetate) supported a more diverse population of microbes in anode placed above cathodes [30]. Based on proton transfer rate analysis in a MEC, proton transfer limited overall hydrogen production and the anode was capable of metabolizing the substrate and transferring electrons to the cathode at higher rates compared to the proton transfer rate [53]. Therefore, it was 
reasonable to evaluate the influence of electrode placement and position on the functions and performance of bioelectrochemical systems.

\subsection{Application potential of $M E-A D$ reactors}

Recently, a new concept of coupling microbial electrolysis and anaerobic digestion has become a promising method for $\mathrm{CO}_{2}$ reduction and leads to minimize the cost of biogas upgrading technology [54]. This is innovative in the field of bioelectrochemical systems and is gaining gradual success. In the present work, this integrated type of reactor facilitates bioelectrochemical enhancement of waste organic degradation and methane production. It was found that the efficiencies of COD removal and its conversion to electrons were potentially determined by electrode position and anode/cathode arrangement in the direction of wastewater flow. Functional communities conducting organic oxidation, electron recovery and methane production accordingly colonized on the anode and cathode. The microbial structure shifted on various locations of electrode in thus upflow anaerobic reactors, leading to variety of methane yields. Supplying extra electron or $\mathrm{H}_{2}$ by microbial electrolysis to anaerobic digestion process can enhance the production of $\mathrm{CH}_{4}$ [30], and thereby upgrade biogas production by converting $\mathrm{CO}_{2}$ into $\mathrm{CH}_{4}$ [54] for simultaneous wastewater treatment. Integration of two significant processes can relatively cut down the cost for reactor construction and wastewater treatment.

\section{Conclusions}

Electrode placements appeared to be significant hydrodynamic parameters for reactor performance. Reactors with electrodes arranged at the bottom were better than those with electrodes at the top, with S4 reactor being the best than the other three reactors with maximum COD, TOC and Carbohydrate removal efficiencies of $92.1 \%, 64.2 \%$ and 98.9\% respectively. Methane production rate (MPR) and methane yield (MY) were also high with $304.5 \mathrm{mLCH}_{4} /$ Lreactor/day and $275.8 \mathrm{~mL} /$ gCOD respectively at $36 \mathrm{~h}$ HRT. The integrated reactors can be operated with electrodes placed at the bottom for a better performance. Microbial community prevalence justified the results of the study, where oxidative Class Bacilli and Genus Lactococcus dominated the S4 reactor biofilms and electrogens Class Clostridia and Deltaproteobacteria and Genus Geobacter and Desulfovibrio prevailed on the biofilms of S3 reactor. Understanding the microbial presence and their relationship with reactor performance would serve as a key scientific question for understanding the performance of these reactors.

\section{Acknowledgement}

This research was supported by the following grants- National Natural Science Foundation of China (No. 51578534), and Youth Innovation Promotion Association CAS (No. 2017062), and the National Key Research and Development Program (No. 2016 YFC0401102-2).

\section{Appendix A. Supplementary material}

Supplementary data associated with this article can be found, in the online version, at http://dx.doi.org/10.1016/j.apenergy.2017.10.026.

\section{References}

[1] Salman CA, Schwede S, Thorin E, Yan J. Enhancing biomethane production by integrating pyrolysis and anaerobic digestion processes. Appl Energy 2017.

[2] Nguyen MT, Yasin NHM, Miyazaki T, Maeda T. Enhancement of sludge reduction and methane production by removing extracellular polymeric substances from waste activated sludge. Chemosphere 2014;117:552-8.

[3] Clauwaert P, Toledo R, van der Ha D, Crab R, Verstraete W, Hu H, et al. Combining biocatalyzed electrolysis with anaerobic digestion. Water Sci Technol 2008;57:575-9.
[4] Cai W, Han T, Guo Z, Varrone C, Wang A, Liu W. Methane production enhancement by an independent cathode in integrated anaerobic reactor with microbial electrolysis. Bioresource Technol 2016;208:13-8.

[5] Geppert F, Liu D, van Eerten-Jansen M, Weidner E, Buisman C, ter Heijne A Bioelectrochemical power-to-gas: state of the art and future perspectives. Trends Biotechnol 2016.

[6] Xu H, Wang K, Holmes DE. Bioelectrochemical removal of carbon dioxide (CO 2): An innovative method for biogas upgrading. Bioresource Technol 2014;173:392-8.

[7] Feng Y, Zhang Y, Chen S, Quan X. Enhanced production of methane from waste activated sludge by the combination of high-solid anaerobic digestion and microbial electrolysis cell with iron-graphite electrode. Chem Eng J 2015;259:787-94.

[8] Liu W, Cai W, Guo Z, Wang L, Yang C, Varrone C, et al. Microbial electrolysis contribution to anaerobic digestion of waste activated sludge, leading to accelerated methane production. Renew Energy 2016;91:334-9.

[9] Trapero JR, Horcajada L, Linares JJ, Lobato J. Is microbial fuel cell technology ready? An economic answer towards industrial commercialization. Appl Energy 2017; 185:698-707.

[10] Pandey P, Shinde VN, Deopurkar RL, Kale SP, Patil SA, Pant D. Recent advances in the use of different substrates in microbial fuel cells toward wastewater treatment and simultaneous energy recovery. Appl Energy 2016;168:706-23.

[11] Linji X, Wenzong L, Yining W, Aijie W, Shuai L, Wei J. Optimizing external voltage for enhanced energy recovery from sludge fermentation liquid in microbial electrolysis cell. Int J Hydrogen Energy 2013;38:15801-6.

[12] Liu C, Liu W, Liu J, Zhou X, Wang A, Nan J. The effect of a short term biofilmaeration treatment on energy recovery in microbial electrolysis cells. RSC Adv 2015;5:69714-9.

[13] Zhang Y, Angelidaki I. Microbial electrolysis cells turning to be versatile technology: recent advances and future challenges. Water Res 2014:56:11-25.

[14] Bo T, Zhu X, Zhang L, Tao Y, He X, Li D, et al. A new upgraded biogas production process: coupling microbial electrolysis cell and anaerobic digestion in singlechamber, barrel-shape stainless steel reactor. Electrochem Commun 2014;45:67-70.

[15] Wang A, Liu W, Cheng S, Xing D, Zhou J, Logan BE. Source of methane and methods to control its formation in single chamber microbial electrolysis cells. Int $\mathrm{J}$ Hydrogen Energy 2009;34:3653-8.

[16] Cheng S, Xing D, Call DF, Logan BE. Direct biological conversion of electrical current into methane by electromethanogenesis. Environ Sci Technol 2009;43:3953-8.

[17] Sangeetha T, Guo Z, Liu W, Cui M, Yang C, Wang L, et al. Cathode material as an influencing factor on beer wastewater treatment and methane production in a novel integrated upflow microbial electrolysis cell (Upflow-MEC). Int J Hydrogen Energy 2016;41:2189-96.

[18] Liu W, He Z, Yang C, Zhou A, Guo Z, Liang B, et al. Microbial network for waste activated sludge cascade utilization in an integrated system of microbial electrolysis and anaerobic fermentation. Biotechnol Biofuels 2016;9:1-15.

[19] Guo Z, Thangavel S, Wang L, He Z, Cai W, Wang A, et al. Efficient methane production from beer wastewater in a membraneless MEC with stacked cathode: the effect of cathode-anode ratio on bioenergy recovery. Energy Fuels 2016.

[20] Lee H-S, Torres CI, Parameswaran P, Rittmann BE. Fate of $\mathrm{H} 2$ in an upflow singlechamber microbial electrolysis cell using a metal-catalyst-free cathode. Environ Sci Technol 2009;43:7971-6.

[21] Liu H, Hu H, Chignell J, Fan Y. Microbial electrolysis: novel technology for hydrogen production from biomass. Biofuels 2010;1:129-42.

[22] Gil-Carrera L, Mehta P, Escapa A, Morán A, García V, Guiot S, et al. Optimizing the electrode size and arrangement in a microbial electrolysis cell. Bioresource Technol 2011;102:9593-8.

[23] Liang D-W, Peng S-K, Lu S-F, Liu Y-Y, Lan F, Xiang Y. Enhancement of hydrogen production in a single chamber microbial electrolysis cell through anode arrangement optimization. Bioresource Technol 2011;102:10881-5.

[24] Liu W, Wang A, Cheng S, Logan BE, Yu H, Deng Y, et al. Geochip-based functional gene analysis of anodophilic communities in microbial electrolysis cells under different operational modes. Environ Sci Technol 2010;44:7729-35.

[25] Liu W, Huang S, Zhou A, Zhou G, Ren N, Wang A, et al. Hydrogen generation in microbial electrolysis cell feeding with fermentation liquid of waste activated sludge. Int J Hydrogen Energy 2012;37:13859-64.

[26] Wang A, Liu W, Ren N, Zhou J, Cheng S. Key factors affecting microbial anode potential in a microbial electrolysis cell for $\mathrm{H} 2$ production. Int J Hydrogen Energy 2010;35:13481-7.

[27] Zhou JZ, Liu WZ, Deng Y, Jiang YH, Xue K, He ZL, et al. Stochastic assembly leads to alternative communities with distinct functions in a bioreactor microbial community. Mbio 2013;4:e00584-612.

[28] Zhou AJ, Liu WZ, Varrone C, Wang YZ, Wang AJ, Yue XP. Evaluation of surfactants on waste activated sludge fermentation by pyrosequencing analysis. Bioresource Technol 2015;192:835-40.

[29] Zhou A, Yang C, Kong F, Liu D, Chen Z, Ren N, et al. Improving the short-chain fatty acids production of waste activated sludge stimulated by a bi-frequency ultrasonic pretreatment. J Environ Biol 2013;34:381.

[30] Cai W, Liu W, Yang C, Wang L, Liang B, Thangavel S, et al. Biocathodic methanogenic community in an integrated anaerobic digestion and microbial electrolysis system for enhancement of methane production from waste sludge. ACS Sustain Chem Eng 2016;4:4913-21.

[31] Zhou A, Du J, Varrone C, Wang Y, Wang A, Liu W. VFAs bioproduction from waste activated sludge by coupling pretreatments with Agaricus bisporus substrates conditioning. Process Biochem 2014;49:283-9.

[32] Varrone C, Van Nostrand JD, Liu W, Zhou B, Wang Z, Liu F, et al. Metagenomicbased analysis of biofilm communities for electrohydrogenesis: From wastewater to 
hydrogen. Int J Hydrogen Energy 2014;39:4222-33.

[33] Baek G, Kim J, Shin SG, Lee C. Bioaugmentation of anaerobic sludge digestion with iron-reducing bacteria: process and microbial responses to variations in hydraulic retention time. Appl Microbiol Biotechnol 2016;100:927-37.

[34] Franke-Whittle IH, Walter A, Ebner C, Insam H. Investigation into the effect of high concentrations of volatile fatty acids in anaerobic digestion on methanogenic communities. Waste Manage 2014;34:2080-9.

[35] Chelliapan S, Wilby T, Sallis P. Effect of hydraulic retention time on up-flow anaerobic stage reactor performance at constant loading in the presence of antibiotic tylosin. Braz J Chem Eng 2011;28:51-61.

[36] Guo ZC, Liu WZ, Yang CX, Gao L, Thangavel S, Wang L, et al. Computational and experimental analysis of organic degradation positively regulated by bioelectrochemistry in an anaerobic bioreactor system. Water Res 2017;125:170-9.

[37] Liu WZ, Cai WW, Ma AZ, Ren G, Li ZL, Zhuang GQ, et al. Improvement of bioelectrochemical property and energy recovery by acylhomoserine lactones (AHLs) in microbial electrolysis cells (MECs). J Power Sources 2015;284:56-9.

[38] Cai WW, Zhang ZJ, Ren G, Shen QX, Hou YN, Ma AZ, et al. Quorum sensing alters the microbial community of electrode-respiring bacteria and hydrogen scavengers toward improving hydrogen yield in microbial electrolysis cells. Appl Energy 2016;183:1133-41.

[39] Ge Z, Ping Q, Xiao L, He Z. Reducing effluent discharge and recovering bioenergy in an osmotic microbial fuel cell treating domestic wastewater. Desalination 2013;312:52-9.

[40] Pasupuleti SB, Srikanth S, Dominguez-Benetton X, Mohan SV, Pant D. Dual gas diffusion cathode design for microbial fuel cell (MFC): optimizing the suitable mode of operation in terms of bioelectrochemical and bioelectro-kinetic evaluation. J Chem Technol Biotechnol 2016;91:624-39.

[41] Wong MT, Zhang D, Li J, Hui RKH, Tun HM, Brar MS, et al. Towards a metagenomic understanding on enhanced biomethane production from waste activated sludge after pH 10 pretreatment. Biotechnol Biofuels 2013;6:1.

[42] Guo Z, Zhou A, Yang C, Liang B, Sangeetha T, He Z, et al. Enhanced short chain fatty acids production from waste activated sludge conditioning with typical agricultural residues: carbon source composition regulates community functions. Biotechnol Biofuels 2015;8:1-14.

[43] Commault AS, Lear G, Weld RJ. Maintenance of Geobacter-dominated biofilms in microbial fuel cells treating synthetic wastewater. Bioelectrochem 2015;106:150-8.

[44] Liu YJ, Nikolausz M, Wang XC. Biodegradation and detoxication of phenol by using free and immobilized cells of Acinetobacter sp. XA05 and Sphingomonas sp. FG03. J Environ Sci Health Part A 2009;44:130-6.

[45] Wang H, Ren ZJ. Bioelectrochemical metal recovery from wastewater: a review. Water Res 2014;66:219-32.

[46] Freguia S, Masuda M, Tsujimura S, Kano K. Lactococcus lactis catalyses electricity generation at microbial fuel cell anodes via excretion of a soluble quinone. Bioelectrochem 2009;76:14-8.

[47] Zheng X, Su Y, Li X, Xiao N, Wang D, Chen Y. Pyrosequencing reveals the key microorganisms involved in sludge alkaline fermentation for efficient short-chain fatty acids production. Environ Sci Technol 2013;47:4262-8.

[48] Yang C, Liu W, He Z, Thangavel S, Wang L, Zhou A, et al. Freezing/thawing pretreatment coupled with biological process of thermophilic Geobacillus sp. G1: Acceleration on waste activated sludge hydrolysis and acidification. Bioresource Technol 2015;175:509-16.

[49] Jiang Y, Su M, Li D. Removal of sulfide and production of methane from carbon dioxide in microbial fuel cells-microbial electrolysis cell (MFCs-MEC) coupled system. Appl Biochem Biotechnol 2014;172:2720-31.

[50] Siegert M, Li X-F, Yates MD, Logan BE. The presence of hydrogenotrophic methanogens in the inoculum improves methane gas production in microbial electrolysis cells. Front Microbiol 2015;5:778.

[51] Patil SA, Arends JBA, Vanwonterghem I, van Meerbergen J, Guo K, Tyson GW, et al. Selective enrichment establishes a stable performing community for microbial electrosynthesis of acetate from $\mathrm{CO}_{2}$. Environ Sci Technol 2015;49:8833-43.

[52] MallaáShrestha P. A new model for electron flow during anaerobic digestion: direct interspecies electron transfer to Methanosaeta for the reduction of carbon dioxide to methane. Energy Environ Sci 2014;7:408-15.

[53] Tartakovsky B, Mehta P, Santoyo G, Guiot SR. Maximizing hydrogen production in a microbial electrolysis cell by real-time optimization of applied voltage. Int $\mathrm{J}$ Hydrogen Energy 2011;36:10557-64.

[54] Geppert F, Liu DD, van Eerten-Jansen M, Weidner E, Buisman C, ter Heijne A Bioelectrochemical power-to-gas: state of the art and future perspectives. Trends Biotechnol 2016;34:879-94. 